\title{
Studi Eksploratif Bahan Ajar Cello Berbasis Metode Suzuki
}

\author{
Nandya Abror Nurmusabih \\ Alumni Jurusan Musik FSP Institut Seni Indonesia Yogyakarta \\ Hari Martopo \\ Lektor Kepala, Jurusan Musik, FSP, Institut Seni Indonesia Yogyakarta \\ Ayu Tresna Yunita \\ Lektor Jurusan Musik FSP Institut Seni Indonesia Yogyakarta
}

\begin{abstract}
Suzuki method is a method of learning that emphasizes the importance of music education musical talent as early as possible for children to use the native language (mother tongue). This method is widely misunderstood by the public simply by using a curriculum book, without applying the philosophy of its creator, Shinichi Suzuki is educated with affection Nurtured by Love and his theory that Talent Education. The Suzuki Method exploration objectives are: (1) to enrich the teaching materials cellobased Suzuki Cello Method using an exploratory method which the research methods used to study the unknown, not yet understood, and not recognized properly, (2) to promote the Suzuki Method in learning the cello. The conclusions are: (1) the enrichment of teaching material cello using the Suzuki Method exploratory method, (2) exploratory method is applied to the enrichment of cello teaching materials as an attempt to socialize the Suzuki Method
\end{abstract}

.Keywords: Music; Aesthetics; Autonomic; heteronomic.

\begin{abstract}
Abstrak
Metode Suzuki merupakan metode pembelajaran musik yang menekankan pentingnya pendidikan bakat musik sedini mungkin untuk anak-anak dengan menggunakan bahasa ibu (mother tongue). Metode ini banyak disalahartikan oleh masyarakat hanya dengan menggunakan kurikulum buku saja, tanpa menerapkan filosofi dari penciptanya, Shinici Suzuki yaitu dididik dengan kasih sayang Nurtured by Love (dididik dengan kasih sayang) dan teorinya yaitu Talent Education (pendidikan bakat). Tujuan eksplorasi Metode Suzuki ini yaitu: (1) untuk memperkaya bahan ajar cello berbasis Metode Suzuki Cello menggunakan metode eksploratif yaitu metode penelitian yang digunakan untuk meneliti sesuatu yang belum diketahui, belum dipahami, dan belum dikenali dengan baik, (2) untuk mensosialisasikan Metode Suzuki dalam pembelajaran cello. Kesimpulan yang dapat diambil adalah: (1) pengayaan bahan ajar cello dalam Metode Suzuki menggunakan metode eksploratif, (2) metode eksploratif yang diterapkan pada pengayaan bahan ajar cello sebagai upaya mensosialisasikanera.
\end{abstract}

Kata kunci: Musik; Estetika; Autonomis; heteronomis.

\section{Pengantar}

Dewasa ini mulai tumbuh kesadaran orangtua dalam memberikan kesempatan kepada anak-anaknya untuk mempelajari musik walaupun tujuannya bukan sematamata untuk menjadi pemusik profesional, tetapi lebih ditekankan untuk pembentukan watak baik. Tumbuhnya kesadaran orangtua itu ditunjang oleh banyaknya informasi yang mudah diserap tentang manfaat musik dari hasil penelitian yang sudah dilakukan. Sarana untuk mempelajari musik juga telah tersedia, baik berupa instrumen musik maupun tempat kursus-kursus musik yang menyediakan berbagai pilihan bagi orangtua 
dan anak dalam mempelajari instrumen yang diminati.

Pada umumnya orangtua mendorong anaknya untuk belajar instrumen cello ketika anak sudah dewasa. Hal ini disebabkan orangtua beranggapan instrumen cello adalah instrument musik yang berukuran cukup besar dan hanya bisa dimainkan anak dewasa, padahal instrumen cello memiliki beragam ukuran untuk berbagai usia dan postur tubuh seseorang. Belajar cello sejak dini seharusnya tidak lagi mempunyai halangan yang berarti, karena sudah ada metode untuk belajar cello, antara lain adalah Metode Suzuki untuk Cello.

Metode Suzuki didesain sebagai cara praktis belajar musik sejak usia dini, tetapi masih banyak orang yang beranggapan bahwa musik sulit dipelajari dan hanya untuk orang-orang yang berbakat saja. Bakat dianggap sebagai hal yang pokok dalam belajar musik, artinya tanpa bakat seseorang tidak mungkin berhasil dalam belajar musik. Padahal bakat itu tidak selalu lahir secara turun temurun, lebih tercipta karena pengaruh lingkungan, seperti yang diungkapkan oleh Shinichi Suzuki bahwa bakat tidak tercipta sejak lahir, "Talent is no accident of birth" (Suzuki, 1983: iv). Metode itu perlu partisipasi orangtua sebagai guru atau pendamping anaknya selama berlatih musik di rumah.

Metode Suzuki dibangun berdasarkan atas filosofi Shinichi Suzuki yaitu Nurtured by Love (dididik dengan kasih sayang), dan teorinya yaitu Talent Education (pendidikan bakat) (Powell, 1988: 6). Di Indonesia filosofi dan teori itu belum banyak diketahui baik oleh guru, orang tua apalagi murid. Kurangnya sosialisasi Metode Suzuki Cello bagi guru membuat guru kurang memahami mengenai filosofi dan teori metode ini, sehingga rata-rata guru hanya memanfaatkan buku Metode Suzuki Cello sebagai bahan ajar belajar cello, tanpa mempelajari filosofi dan teori yang sebenarnya.
Shinichi Suzuki berpendapat bahwa anak menguasai bahasa ibu berdasarkan lingkungan di sekitar mereka, "children can learn their own languages that is stimulated by the environment" (Bigler dan LloydWatts, 1998:2). Orangtua mereka adalah pengajar utamanya. Tidak ada kata "luluse maupun "gagale dalam mempelajari bahasa ibu mereka dan tidak ada batasan waktu berapa lama anak akan dapat belajar berbicara. Semua proses belajar akan dimulai oleh remaja itu sendiri dan setiap remaja berkembang sesuai dengan kemam-puannya masing-masing. Orangtua dan keluarga lain-nya akan selalu memperbaiki kesalahan anakanaknya. Anakakan lebih mudah da-lam mempelajari musik jika musik menjadi bahasa ibu yang selalu ada dalam kehidupan mereka, dengan orangtua memperdengarkan musik pada anaknya sehari-hari.

Tentang bakat, sebenarnya Metode Suzuki dapat dijadikan acuan pada metode pembelajaran bidang yang lain selain musik, karena dalam metode itu terdapat teori yaitu pendidikan bakat. Bakat tidak akan tercipta begitu saja namun membutuhkan waktu dan motivasi dari orang lain. Anak sebaiknya tidak dipaksa untuk memiliki suatu keterampilan karena keterampilan akan muncul seiring dengan kemauan belajar dari anak itu sendiri. Kemauan belajar muncul jika anak dididik dengan kasih sayang serta motivasi dari orangtua dan keluarga terdekat.

Dalam menerapkan Metode Suzuki, penulis menggunakan buku pegangan yang berjudul Suzuki Cello School Volume 1 sebagai acuan untuk melatih anak dalam pembelajaran cello. Buku ini berisi lagu-lagu aransemen Shinichi Suzuki dalam instrumen cello. Di Indonesia Metode Suzuki untuk cello belum terlalu populer dibandingkan dengan Metode Suzuki untuk biolin. Berdasarkan pengamatan penulis, Metode Suzuki Cello kurang populer di Indonesia karena lagulagu yang digunakan sebagai bahanajar cello di dalam buku Suzuki Cello masih minim dan kurang familiar di telinga anak Indonesia. 
Untuk mengatasi hal ini, penulis ingin mengeksplorasi lagu-lagu Indonesia yang familiar di telinga anak Indonesia dengan tujuan untuk memperkaya bahan ajar cello dalam Metode Suzuki. Hal ini diharapkan mampu membuat Metode Suzuki Cello lebih populer di Indonesia.

\section{Pembahasan}

Pembatasan masalah penelitian Studi Eksploratif Bahan Ajar Cello Berbasis Metode Suzuki adalah pembelajaran cello tingkat dasar. Buku yang digunakan penulis adalah buku Suzuki Cello Volume 1. Penulis menganalisis buku tersebut dan mendapatkan hasil analisis berupa konsep tangga nada, pemilihan pola ritmis, teknik menggesek cello, teknik posisi tangan kiri.

Shinici Suzuki menggunakan tiga tangga nada mayor, yaitu tangga nada " $\mathrm{D}$ ", " $G$ " dan " $C$ " dua oktaf. Suzuki dalam hal ini menekankan dasar menggesek cello melalui teknik gesekan Arco: gesek turun (down) dan gesek naik (up). Suzuki juga mengenalkan teknik tangan kanan yaitu Pizzicato: memetik senar. Teknik ini tidak bisa terlalu cepat atau terlalu tinggi (terkadang pada teknik Pizzicato tangan kiri bisa digunakan untuk kecepatan tertentu). Teknik selanjutnya adalah Legato: beberapa nada dalam satu arah gesekan. Teknik ini digunakan untuk efek yang lembut dan ekspresif. Teknik tangan kanan terakhir yang ditekankan oleh Suzuki adalah teknik Staccato: tiap nada dimainkan pendek, efek terdengar terang dan bersih.

Dari hasil menganalisis buku Suzuki Cello Volume 1, penulis menjadikan hasil analisis tersebut sebagai dasar dan acuan dalam mengeksplorasi bahan ajar cello berbasis Metode Suzuki. Dari berbagai gagasan metode Suzuki adalah teknik-tekbnik dasar posisi tangan kiri untuk memainkan tangga nada. Teknik tangan kiri yang ditekankan Shinici Suzuki adalah Posisi Satu (First Position).

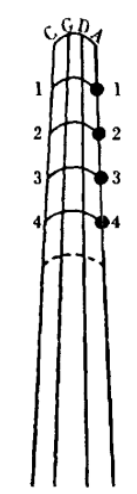

Ilustrasi 1.

Tabulatur Posisi Satu pada dawai pertama.

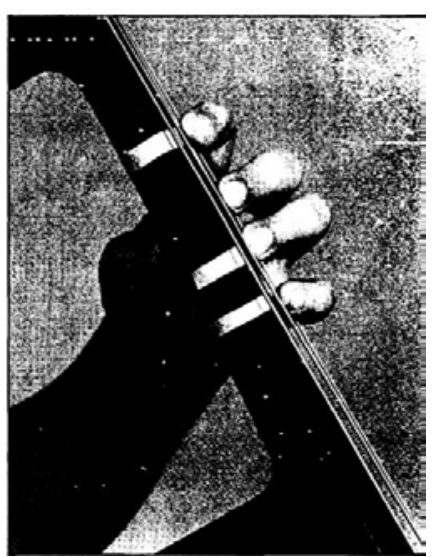

Ilustrasi 2.

Posisi Satu (First Position)

Teknik tangan kiri yang terakhir adalah Extension dengan formula: move 2,3,4 and thumb one-half step higher, keep thumb under 2. Bring elbow forward for Extension, yang maksudnya adalah gerakkan jari 2, 3, 4, dan jempol dengan jarak satu-setengah lebih tinggi, pertahankan jempol di belakang jari 2. Bawa siku ke depan untuk perregangan.

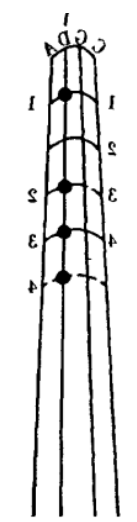

Ilustrasi 3

Tabulatur posisi peregangan jari kiri. 


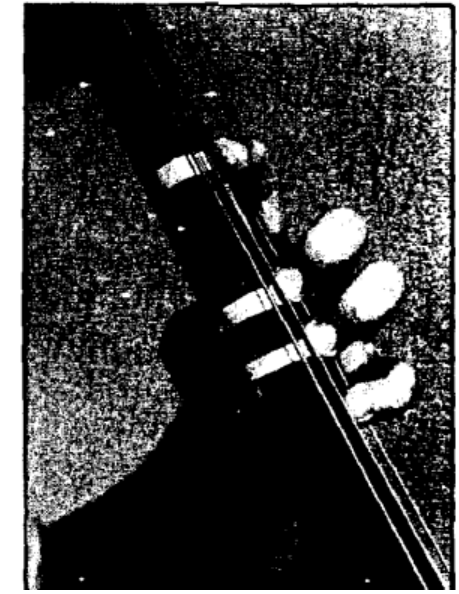

Ilustrasi 4.

Posisi Lebar (Extension Position)

Langkah awal penulis dalam mengeksplorasi lagu-lagu yang ada dalam buku Suzuki Cello Volume 1 adalah dengan membuat rangkaian lagu-lagu duet cello. Pembuatan duet cello diharapkan dapat menjadi Ilustrasian awal penulis dalam mengeksplorasi bahan ajar yang lainnya. Penulis juga mengambil lagu daerah (folksong) dari Indonesia sebagai bahan eksplorasilayaknya Suzuki mengambil lagulagu daerah dari berbagai Negara. Tujuan penulis mengambil lagu-lagu daerah dari Indonesia yaitu agar bahan ajar cello menjadi lebih banyak, dan pengayaan tersebut juga bertujuan untuk mempermudah anak atau murid dalam mempelajari metode Suzuki, karena lagu-lagu daerah tersebut lebih familiar di telinga anak Indonesia (lihat ilustrasi 5).

Hal penting selanjutnya yang perlu diperhatikan setelah hasil eksplorasi bahan ajar metode Suzuki Cello siap untuk diterapkan, yaitu bagaimana langkah penerapan kepada murid agar murid menguasai bahan ajar cello dengan menerapkan metode pembelajaran yang sesuai dengan metode Suzuki. Berikut ini merupakan langkahlangkah yang harus diperhatikan oleh guru maupun orangtua dalam mendampingi murid dalam mempelajari cello menggunakan metode Suzuki.

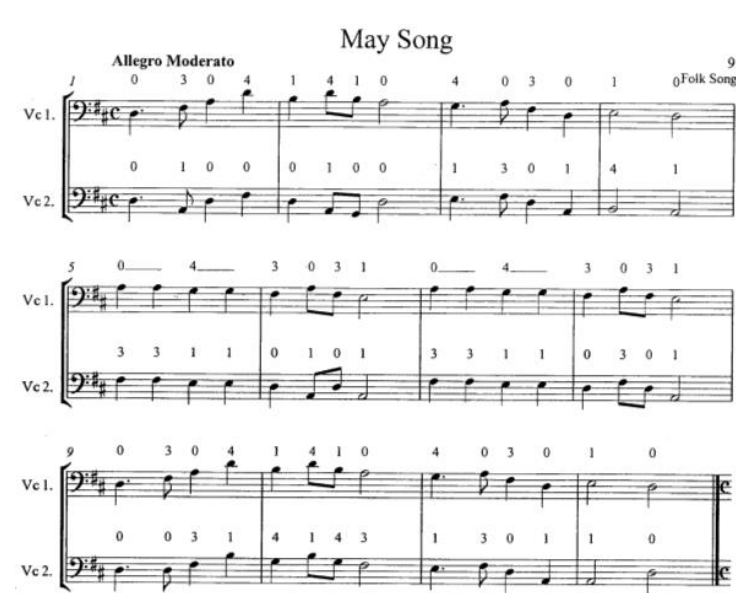

Ilustrasi 5.

Contoh Repertoar Duet Cello Hasil Eksplorasi

Hal penting selanjutnya yang perlu diperhatikan setelah hasil eksplorasi bahan ajar metode Suzuki Cello siap untuk diterapkan, yaitu bagaimana langkah penerapan kepada murid agar murid menguasai bahan ajar cello dengan menerapkan metode pembelajaran yang sesuai dengan metode Suzuki. Berikut ini merupakan langkahlangkah yang harus diperhatikan oleh guru maupun orangtua dalam mendampingi murid dalam mempelajari cello menggunakan metode Suzuki.

Untuk langkah yang pertama, anakanak setiap hari diharuskan mendengarkan rekaman yang sedang dipelajari. Hal ini sangat membantu dalam kemajuannya dan merupakan faktor paling penting dalam mengembangkan keterampilan musiknya. Mereka yang tidak cukup atau kurang mendengarkan akan kurang juga dalam kepekaan musiknya.

Tahap yang kedua, yaitu pembentukan nada dengan cara memproduksi suara yang indah. Seperti juga vokalisasi dipelajari dalam olah vokal, begitupun setelah memperkenalkan hal yang sama pada pelajaran cello sebagai suatu metode baru dalam suatu pendidikan. Setelah itu, pemakaian jenis baru dari paket pelajaran dari murid-murid yang sudah maju dan yang baru mulai bergabung (terpadu) ternyata sangat efektif. 
Murid atau siswa akan mengalami kemajuan yang pesat sambil menikmati pelajarannya.

Untuk tahap ketiga, orang tua harus selalu memberikan perhatian terhadap anaknya saat latihan di rumah. Perhatian yang diberikan oleh orang tua tentu saja sudah ada komunikasi atau pengarahan oleh guru yang mengajar anaknya.

Tahap terakhir yang harus diperhatikan adalah dorongan dari orang tua yang menciptakan lingkungan di rumah agar anak senang berlatih. Setelah itu, seorang anak janganlah melewati sebuah latihan yang baru hanya karena ia telah belajar teknik penjarian dan penggesek pada pelajaran tersebut. Kesanggupannya seharusnya dipupuk lebih jauh pada waktu ia memainkan lagu atau latihan. Suzuki mengatakan: "sekarang setelah engkau mengenal nada, kita dapat melalui dengan suatu usaha yang sangat penting untuk mengembangkan kesanggupannya", dan setelah itu mulai usaha memperbaiki nadanya dan kepekaan musikalnya. Langkah yang berikut adalah juga penting jika anak-anak dapat menyelesaikam atau mengerjakan pekerjaan A secara memuaskan dan ketika diberi pekerjaan $B$, dia tidak boleh melepaskan tugas $\mathrm{A}$, tetapi anak harus melatih tugas A dan tugas B secara bersamasama.

Melatih bahan atau tugas secara terusmenerus akan memungkinkan anak berkembang kepada keterampilan yang lebih tinggi. Keterampilan musik bukanlah keistimewaan atau bakat yang dibawa sejak lahir semata-mata, tetapi merupakan keterampilan yang dapat dikembangkan. Seorang anak yang telah dilatih untuk mengembangkan kecakapannya atau keterampilan musik seperti halnya anak-anak yang dilatih untuk mengembangkan kecakapan berbicara dengan bahasa ibunya. Untuk kebahagiaan anak-anak pada umumnya, Suzuki berharap empat petunjuk pokok tersebut dapat diterapkan secara berkesinambungan.
Sesuai dengan tujuan awal penelitian, yaitu untuk mempopulerkan Metode Suzuki Cello, penulis meng-adakan Home Concert yang didalamnya menuntut murid untuk memainkan lagu-lagu yang ada dalam buku Suzuki Cello Volume 1 dan juga repertoar hasil eksplorasi bahan ajar cello berbasis Metode Suzuki.

Home Concert ini sebenarnya merupakan perwujudan sebuah ujian tersirat yang bertujuan untuk meningkatkan semangat murid dalam menguasai seluruh bahan ajar cello.

\section{Penutup}

Pengayaan bahan ajar cello menggunakan metode eksploratif dapat digunakan sebagai suplemen bahan ajar cello berbasis Metode Suzuki bagi para guru cello. Metode eksploratif ini sebenarnya bisa diterapkan oleh para guru untuk meng-eksplorasi bahan ajar sesuai dengan instru-men yang dipegangnya.

Secara umum, metode Suzuki kurang populer di Indonesia. Oleh karena itu, diharapkan dengan adanya eksplorasi bahan ajar cello yang diterapkan melalui elemen edukasi, metode Suzuki dapat menjadi lebih populer di Indonesia. Berdasarkan uraian pada bab-bab sebelumnya, maka dapat diambil kesimpulan bahwa:

1. Guru harus memiliki strategi agar anak menyukai belajar cello dengan Metode Suzuki salah satunya dengan berani mengeksplorasi bahan ajar cello berbasis Metode Suzuki.

2. Kaitannya dengan tujuan untuk mempopulerkan Metode Suzuki, guru secara rutin mengadakan home concert sebagai bentuk elemen edukasi.

Pembelajaran musik di Indonesia masih banyak yang hanya bertujuan mencetak murid untuk berketerampilan musik yang tinggi tanpa memperhatikan keadaan murid. Sehingga banyak murid 
yang dapat memainkan karya yang sulit tanpa ada penjiwaan terhadap lagu. Dengan Metode Suzuki orangtua disarankan untuk memperkenalkan anak pada musik sedini mungkin agar musik menjadi bahasa ibu mereka. Guru juga disarankan untuk mengajar musik dengan menyesuaikan keadaan murid khususnya yang masih anakanak yaitu kebiasaan mereka yang sering meniru dan bermain, misalnya saja guru memberi contoh dengan memainkan bahan musik terlebih dahulu agar murid dapat mengenal bahan yang akan dilatihnya serta memainkannya dengan teknik yang benar dan penjiwaan yang baik.

Diharapkan penulisan skripsi ini akan menjadi inspirasi bagi semua pihak terutama Suzuki Association of Indonesia. Semoga skripsi ini dapat dijadikan masukan dalam pengembangan bahan ajar cello berbasis Metode Suzuki dan pembelajaran musik di Indonesia dapat lebih maju dari sebelumnya.

\section{Referensi}

Honda, Masaaki. 1984. Shinici Suzuki: Man of Love. Diterjemahkan dalam bahasa Inggris oleh: Kyoko Selden. U.S.A.: Birch Tree Group Ltd.

Hurlock, Elizabeth B. 1980. Psikologi Perkembangan. Edisi Kelima. Diterjemahkan oleh: Dra. Istiwidayanti dan Soedjarwo, Jakarta: Penerbit Erlangga.

Martopo, Hari. 2005. “Metode Pembelajaran Biola Suzuki Ditinjau dari Perspektif
Quantum". Jurnal Penciptaan dan Pengkajian Seni. Program Pascasarjana. Institut Seni Indonesia Yogyakarta.

Miles, Matthew B. dan A. Michael Huberman. 1992. Analisis Data Kualitatif: Buku Sumber Tentang Metode-metode Baru. Diterjemahkan oleh: Tjetjep Rohendi Rohidi. Jakarta: Penerbit Universitas Indonesia.

Moleong, Lexy J. 2012. Metode Penelitian Kualitatif. Edisi Revisi. Cetakan ketigapuluh. Bandung: PT Remaja Rosdakarya.

Sacks, Oliver. 2013. Musikofilia: Kisah-kisah Tentang Musik dan Otak. Diterjemahkan oleh: B. Sendra Tanuwidjaja. Jakarta: PT Indeks.

Shepheard, Lois. 2012. Memories of Dr. Shinici Suzuki, Son of His Environment. Australia: Glass House Books.

Suryana, 2010. “Metode Penelitian: Model Praktis Penelitian Kuantitatif dan Kualitatif". Universitas Pendidikan Indonesia. Bandung.

Suzuki, Shinici. 1983. Nurtured by Love: The Classic Approach to Talent Education. Edisi kedua. Diterjemahkan dalam bahasa Inggris oleh: Waltraud Suzuki. U.S.A.: Summy-Bichard Inc. c/o. Alfred Publishing Co.,Inc.

Suzuki, Shinici. 1993. How to Teach Suzuki Cello. Japan: Dr. Suzukiees Talent Education Institute. 